\title{
PENERAPAN METODE CERTAINTY FACTOR UNTUK SISTEM PAKAR DIAGNOSIS KERUSAKAN PADA MOBIL DAIHATSU
}

\author{
Dwi Adi Iswara, Ahmad Faisol, Renaldi Primaswara Prasetya \\ Program Studi Teknik Informatika S1, Fakultas Teknologi Industri \\ Institut Teknologi Nasional Malang, Jalan Raya Karanglo km 2 Malang, Indonesia \\ 1718037@scholar.itn.ac.id
}

\begin{abstract}
ABSTRAK
Sistem pakar adalah program komputer yang meniru proses berpikir dan pengetahuan pakar untuk memecahkan masalah tertentu. Sistem pakar dapat diaplikasikan pada berbagai macam sector yaitu pada sektor otomotif. contohnya untuk diagnosis kerusakan pada mobil. PT. Astra Daihatsu adalah satu-satunya perwakilan merek mobil Daihatsu di Indonesia yang berwenang untuk mengimpor, merakit dan memproduksi kendaraan merek Daihatsu di Indonesia. penggunanya di indonesia cukup banyak dengan beberapa variannya. Namun tidak semua penggunanya mengerti cara merawat kendaraannya, kebanyakan hanya mengerti cara memakainya saja tanpa memerhatikan perawatannya. Padahal dengan melakukan perawatan dapat mengurangi resiko kerusakan pada mobil. Pada penelitian ini, penulis mendiagnosa kerusakan pada mobil daihatsu dengan membangun sistem pakar yang dapat menganalisa gejala kerusakan yang terjadi pada mobil menjadi keputusan nama penyakit dengan metode certainty factor untuk menghitung probabilitas hasil diagnosa. implementasi metode ini menggunakan bahasa pemrograman PHP dan media penyimpan databasenya menggunakan MYSQL. Data gejala, kerusakan dan solusi pada mobil daihatsu didapatkan dari seorang service advisor di daihatsu malang dan mekanik bengkel anggrek kepanjen. Hasil pengujian Sistem pakar kerusakan mobil daihatsu menunjukan fungsional aplikasi berjalan dengan baik. Pada sistem pakar ini terdapat pengujian yang dilakukan dengan membandingkan hasil perhitungan sistem dengan perhitungan manual. pada perhitungan sistem dan perhitungan manual menunjukkan hasil yang sesuai.
\end{abstract}

Kata Kunci : certainty factor, sistem pakar, certainty factor, kerusakan kendaraan daihatsu.

\section{PENDAHULUAN}

Sistem pakar adalah program komputer yang meniru proses berpikir dan pengetahuan pakar untuk memecahkan masalah tertentu. Sistem pakar diatur sedemikian rupa sehingga mencoba meniru kemampuan manusia untuk memecahkan masalah tertentu dalam bentuk heuristik. Salah satu metode dalam sistem pakar adalah faktor keamanan. Certainty Factor adalah metode yang menunjukkan dalam bentuk metrik yang umum digunakan dalam sistem pakar apakah suatu fakta itu benar atau tidak pasti. Metode ini bekerja sangat baik untuk sistem pakar mendiagnosis sesuatu yang tidak pasti. Certainty factor diperkenalkan oleh Shortliffe Buchanan dalam pembuatan MYCIN. Certainty Factor (CF) adalah nilai parameter klinis yang diberikan oleh MYCIN untuk menunjukkan tingkat kepercayaan.

PT Astra Daihatsu Motor atau biasa disingkat ADM adalah satu-satunya perwakilan merek mobil Daihatsu di Indonesia. Seperti ATPM, ADM adalah satu-satunya perusahaan yang berwenang untuk mengimpor, merakit dan memproduksi kendaraan merek Daihatsu di Indonesia. Kendaraan Daihatsu didistribusikan sepenuhnya oleh Astra melalui Divisi Sales Operation Daihatsu yang memiliki 137 jaringan penjualan di seluruh Indonesia, 71 di antaranya merupakan outlet penjualan langsung Astra.

Dengan semakin luasnya jaringan penjualan daihatsu di Indonesia dan naiknya penjualaan unit mobilnnya, maka pengguna kendaraan bermerk daihatsu di Indonesia akan semakin banyak, namun tidak semua pengguna mobil tersebut tau bagaimana melakukan perawatan kendaraannya, kebanyakan hanya mengerti pemakaian saja, padahal dengan perawatan yang baik maka tidak akan terjadi kerusakan yang serius. Jika sudah terjadi kerusakan biasanya pengguna susah untuk mengidentifikasi kerusakan yang terjadi, maka dari itu sistem pakar ini dapat membantu pengguna agar dapat melakukan diagnosis awal kerusakan pada mobil. Aplikasi sistem pakar ini tidak berarti menggantikan mekanik ataupun pakar mobil, namun hanya membantu pengguna untuk memperkirakan kerusakan yang terjadi pada mobil pengguna.

\section{TINJAUAN PUSTAKA}

\subsection{Penelitian Terdahulu}

Penelitian tentang Metode Certainty Factor telah banyak dilakukan dan dituliskan dalam jurnal, diantaranya Bily Cahyadi (2018) yang melakukan penelitian tentang "Sistem Pakar Diagnosis Penyakit Paru-Paru Menggunakan Metode Certainty Factor Dengan Mesin Inferensi Forward Chaining Berbasis Android". Penelitian ini dilakukan karena masyarakat masih banyak yang belum mengetahui tentang gejala penyakit paru-paru, dan seringkali dianggap sepele. Misal batuk, nyeri di dada, badan lemas serta sesak nafas. Padahal penyakit paru-paru bisa sangat beresiko menyebabkan kematian. Maka 
dari itu dibuat sistem pakar ini untuk alternatif konsultasi ke dosen bagi masyarakat umum. Untuk media yang digunakan adalah berbasis android. Untuk peralatan yang digunakan untuk membuat sistem, penulis menggunakan Tools Android Studio Versi 2.1.2 serta menggunakan metode certainty factor.

Selanjutnya Syahri Perdana Kurniawan,(2018), meneliti tentang "Sistem Pakar Untuk Diagnosis Penyakit Anemia Menggunakan Metode Certainty Factor Dengan Mesin Inferensi Forward Chaining Berbasis Web". Pada jurnal ini penulis bertujuan untuk membantu pengguna untuk diagnosis penyakit anemia karena di Indonesia masih banyak sekali yang terkena anemia namun tidak sadar dan sering mengabaikan gejala-gejala yang dialami. Oleh karena itu penelitian ini bertujuan membantu penggunanya agar dapat mengetahui gejala penyakit anemia sehingga dapat mengurangi orang yang terkena penyakit anemia. Untuk metode yang digunakan adalah certainty factor dan untuk perangkat yang digunakan yaitu Bahasa pemrograman PHP dan Mysql sebagai databasenya.

Christop Gulo dan, Nelly Astuti Hasibuan (2017) dalam artikelnya mambahas masalah tentang "Perancangan Sistem Pakar Deteksi Kerusakan Mobil Honda Cr-V Dengan Menerapkan Metode Certainty Factor". Penelitian ini dibuat agar dapat membantu pada pengguna agar dapat mengetahui kerusakan yang terjadi pada mobil, agar penggunadapat melakukan tindakan yang efisian untuk penanganan kerusakannya, karena dapat meningkatkan jaminan keselamatan berkendara serta kenyamanan penggunanya. Untuk metode yang digunakan adalah certainty factor.

Pada judul penelitian yang dilakukan oleh Kristyanto Nugroho dan , Sumiati (2020) "Sistem Pakar Diagnosa Kerusakan Kendaraan Pada Mobil Wuling Confero S Menggunakan Metode Certainty Factor", sistem pakar ini dibangun agar dapat mempermudah para pengguna mobil khususnya pegguna wuling confero s agar dapat melakukan diagnois awal pada mobilnya. Untuk bagian yang dapat dilakukan diagnosa ada beberapa yaitu seperti bagian mesin maupun bagian yang lain, sehingga dapat membantu pengguna agar dapat mengetahui permasalahan yang terjadi pada kendaraannya.

Selanjutnya dengan penelitian yang dilakukan oleh Ida Bagus Dhany Satwika,(2012) "Rancang Bangun Sistem Diagnosa Kerusakan Pada Mobil Menggunakan Metode Forward Chaining”. Pada penelitian ini memiliki tujuan untuk membantu pengguna agar dapat melakukan diagnosis kerusakan pada mobil mereka berdasarkan gejala-gejala maupun keluhan yang dialami oleh pengguna pada mobilnya. Alasan peneliti menggunakan metode forward chaining ini karena metode ini bekerja dengan dengan menumpulkan/menyatukan informasi lalu kemudian mencari kesimpulan apa yang dapat diambil dari informasi tersebut. Pada jurnal ini pengguna dapat mendapatkan hasil diagnosis berupa kemungkinan kerusakan yang dialami pada mobil pengguna, serta memberikan rekomendasi bengkel.

Diharapkan dengan diadakannya penelitian ini bisa menghasilkan suatu sistem pakar yang dapat digunakan untuk mendiagnosis kerusakan pada mobil Daihatsu sehingga dapat membantu pengguna untuk mengetahui permasalahan yang terjadi pada kendaraannya jika suatu waktu terjadi kendala.

\subsection{Dasar Teori}

\subsubsection{Sistem Pakar}

Menurut Syahri Perdana Kurniawan (2018), sistem pakar merupakan cabang Artificial Intelligence (AI) yang cukup tua, sejak sistem ini mulai berkembang pada pertengahan tahun 1960-an, dan sistem pakar yang pertama kali muncul adalah general purpose problem solver (GPS). dikembangkan oleh Newel dan Simon. Sejauh ini, banyak sistem pakar telah dikembangkan, seperti MYCIN untuk diagnosis penyakit, DENDRAL untuk mengidentifikasi struktur molekul campuran yang tidak diketahui, XCON dan XSEL untuk mengkonfigurasi sistem komputer besar, SOPHIE untuk menganalisis sirkuit elektronik, Prospector dalam geologi untuk menemukan dan menemukan endapan, FOLIO digunakan untuk membantu a Untuk membantu manajer membuat inventaris dan keputusan investasi, DELTA digunakan untuk perawatan lokomotif diesel-listrik, dll. Istilah sistem pakar berasal dari istilah sistem pakar berbasis pengetahuan.

\subsubsection{Konsep Dasar Sistem pakar}

Ada enam hal yang menjadi konsep dasar dari sebuah Sistem Pakar, yaitu :

\section{Keahlian (Expertise)}

Keahlian dapat diperoleh dari pelatihan/training, membaca atau dari pengalaman. Keahlian itu meliputi:

a. Fakta-fakta tentang area

b. Teori-teori tentang area

c. Aturan-aturan tentang apa yang harus dilakukan dalam situasi permasalahan yang

d. Strategi global untuk memecahkan

\section{Pakar (Expert)}

Pakar adalah seseorang yang secara luas dianggap sebagai sumber tepercaya untuk teknik atau pengetahuan tertentu dan yang bakatnya adalah menilai dan memutuskan apa yang benar. Yang harus dibawa oleh seorang ahli adalah ia harus mampu mengenali dan merumuskan sesuatu, memecahkan masalah dengan cepat dan tepat, menjelaskan dan menentukan sesuatu, dan seorang ahli harus bisa belajar dari pengalaman 


\section{Pemindahan Keahlian (Transferring \\ Expertise) \\ Tujuan dari sistem pakar adalah untuk} mentransfer keahlian dari seorang pakar ke komputer dan kemudian ke orang lain yang bukan pakar. Proses ini terdiri dari empat kegiatan, yaitu:

a. Mendapatkan pengetahuan Ahli

b. Merepresentasikan pengetahuan ke dalam komputer

c. Memproses pengetahuan untuk menarik kesimpulan.

d. Transfer pengetahuan ke pengguna

Pengetahuan disimpan dalam komputer dalam bentuk komponen yang disebut basis pengetahuan, yang dibagi menjadi dua bagian, yaitu fakta dan aturan.

\section{Menarik Kesimpulan (Inferencing)}

Keistimewaan dari sistem pakar adalah kemampuan nalarnya. Komputer diprogram sehingga dapat membuat kesimpulan. Pengambilan keputusan ini dilaksanakan dalam komponen yang disebut inference engine.

\section{Aturan (Rule)}

Kebanyakan sistem pakar adalah sistem berbasis rule, pengetahuan disimpan dalam bentuk rule-rule sebagai prosedur pemecahan masalah.

\section{Kemampuan Menjelaskan (Explanatin Capability) \\ Keistimewaan lain dari sistem pakar adalah kemampuan menjelaskan darimana asal sebuah solusi/rekomendasi diperoleh.}

\subsubsection{Struktur Sistem Pakar}

Sistem pakar terdiri berdasarkan 2 bagian utama yaitu: lingkungan pengembangan "development environment" \& lingkungan konsultasi "consultation enviroment", lingkungan pengembangan dipakai menjadi pembangunan sistem pakar baik menurut segi pembangunan komponen juga basis pengetahuan. Lingkungan konsultasi dipakai seseorang yang bukan pakar untuk berkonsultasi "Kusumadewi, 2003:113-115".

Komponen-komponen yang terdapat dalam arsitektur/struktur sistem pakar sebagai berikut:

\section{Antarmuka Pengguna "User Interface"}

Antarmuka adalah mekanisme yang digunakan pengguna dan sistem pakar untuk berkomunikasi. Antarmuka menerima informasi dari pengguna dan mengubahnya menjadi bentuk yang dapat diterima oleh sistem. Antarmuka juga menerimanya dari sistem dan menampilkannya dengan cara yang dapat dimengerti oleh pengguna.

\section{Basis Pengetahuan}

Basis data pengetahuan adalah jenis basis data yang digunakan untuk manajemen pengetahuan. Basis data ini menawarkan kemungkinan untuk mengumpulkan, mengatur, dan mengambil kembali pengetahuan yang terkomputerisasi. basis data mengandung pengetahuan untuk pemahaman, formulasi data dan penyelesaian masalah

\section{Akuisis Pengetahuan "Knowledge Acquisition"}

Akuisisi pengetahuan merupakan akumulasi, transfer, dan konversi pengetahuan khusus untuk memecahkan masalah berdasarkan sumber pengetahuan pada program komputer. Dalam proses ini, knowledge engineer mencoba menyerap pengetahuan dan lalu mentransfernya ke basis pengetahuan. Pengetahuan pakar dilengkapi dengan buku, database laporan penelitian dan pengalaman pengguna.

\section{Mesin/Motor Inferensi "Inference Engine"}

Komponen ini berisi tentang pola pikir dan mekanisme penalaran yang digunakan oleh para ahli dalam pemecahan masalah. Mesin inferensi adalah program komputer yang menyediakan metodologi untuk berpikir tentang informasi di basis pengetahuan dan di tempat kerja dan untuk merumuskan kesimpulan.

\section{Workplace/Blackboard}

workplace adalah area kumpulan "working memory" dari memori kerja yang digunakan untuk merekam peristiwa yang sedang berlangsung, termasuk keputusan dari waktu ke waktu

\section{Fasilitas Penjelasan}

Fasilitas Penjelasan adalah komponen tambahan yang meningkatkan kapasitas sistem pakar, digunakan untuk melacak tanggapan dan memberikan penjelasan tentang perilaku sistem pakar secara interaktif melalui pertanyaan.

\section{Perbaikan Pengetahuan}

Para pakar mempunyai kemampuan untuk menganalisis dan menaikkan kinerja, dan kemampuan untuk belajar berdasarkan kinerja mereka. Kemampuan ini krusial pada pembelajaran terkomputerisasi sehingga program bisa menganalisis penyebab keberhasilan dan kegagalan dan juga menilai apakah pengetahuan yang terdapat masih cocok buat dipakai pada masa depan.

\subsubsection{Komponen-komponen mobil}

Menurut Ida Bagus Dhani Satwika (2012) Komponen-komponen mobil merupakan satu kesatuan yang menunjang sistem kerja mesin mobil. Mesin bergerak karena adanya sistem pembakaran dalam (internal combustion engine), yang mengubah energi kimia menjadi energi mekanis dengan 
membakar campuran bensin dan udara, sehingga terjadilah ledakan yang dapat menggerakkan mesin. Secara sederhana, proses kerja masing-masing komponen dalam menunjang kerja secara keseluruhan meliputi sistem pengisian dan pembakaran dalam, sistem transmisi, sistem kemudi, sistem suspensi, sistem rem, sistem kelistrikan, serta sistem pelumasan dan pendinginan.

PT Astra Daihatsu Motor (ADM), yang merupakan entitas asosiasi dengan kepemilikan oleh Perseroan, Daihatsu Motor Co., Ltd. dan Toyota Tsusho Corporation, berperan sebagai agen pemegang merek Daihatsu di Indonesia sekaligus basis produksi utama untuk grup otomotif Daihatsu dan Toyota di luar Jepang. Daihatsu Sales Operation (DSO), mendukung ADM, sebagai distributor tunggal yang menyediakan layanan penjualan dan purnajual untuk seluruh produk Daihatsu yang dipasarkan di Indonesia.

\subsubsection{Certainty Factor}

Certainty factor atau faktor kepastian pertama kali diperkenalkan pada tahun 1975 oleh Shortliffe Buchanan. Faktor kepastian adalah metode pengujian apakah suatu fakta itu benar atau tidak pasti. Metode ini bekerja sangat baik untuk sistem pakar mendiagnosis sesuatu yang salah.

Menurut Prihatini (2011), faktor kepastian kepastian yang diisi oleh ahli, bersama dengan aturan keyakinan ahli dalam hubungan antara antecedent dan consequent. pada aturan kaidah produksi faktor kepastian yang diisikan oleh penggunauntuk menunjukkan besarnya kepercayaan terhadap keberadaan masing-masing elemen dalam antecedent

Certainty Factor (CF) didefinisikan dengan persamaan:

$$
C F_{(H, E)}=M B_{(H, E)} \times M D_{(H, E)}
$$

Keterangan :

$C F_{(H, E)}=$ Faktor kepastian Hipotesis $\mathrm{H}$, yang dipengaruhi oleh gejala E. Besarnya $\mathrm{CF}$ antara 1 dan -1 . Nilai -1 menunjukkan ketidakpercayaan mutlak, sedangkan nilai 1 menunjukkan keyakinan mutlak

$M B_{(H, E)}=$ Ukuran peningkatan kepercayaan pada Hipotesis $\mathrm{H}$ yang disebabkan oleh gejala E.gejala E.

$M D_{(H, E)}=$ Besarnya peningkatan ketidakpercayaan terhadap Hipotesis $\mathrm{H}$ disebabkan oleh gejala E.E.

\subsubsection{Website}

Website adalah kumpulan halaman pada domain yang berisi berbagai informasi yang dapat dibaca dan ditampilkan oleh pengguna Internet menggunakan mesin pencari.

Secara umum, Tampilan awal sebuah website, dapat diakses dari halaman utama (home page) dengan browser dengan memasukkan URL yang benar. Di halaman beranda, itu juga berisi beberapa halaman web turunan yang terhubung satu sama lain.

\section{METODE PENELITIAN}

\subsection{Blok Diagram Sistem}

Blok diagram adalah diagram dari sebuah sistem, dimana bagian utama atau fungsi yang diwakili oleh blok dihubungkan dengan garis, yang menunjukkan hubungan dari blok. proses kerja pada sistem pakar diagnosis kerusakan pada mobil ini menggunakan metode Certainty Factor ditunjukan pada gambar 1

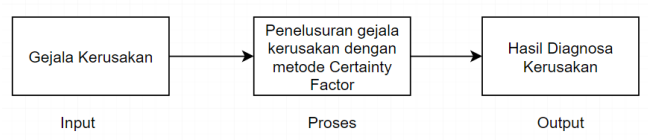

Gambar 1. Blok diagram sistem

\subsection{Flowchart Metode}

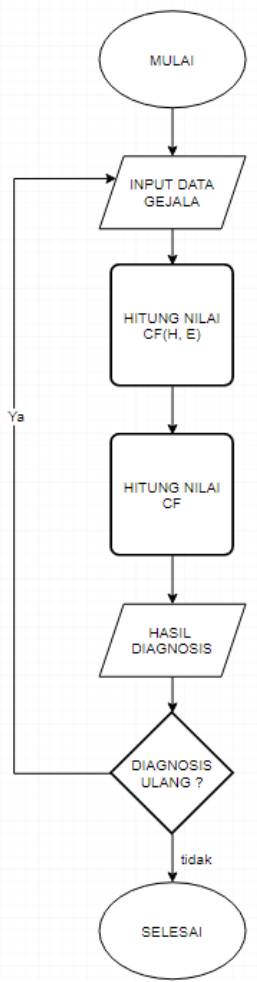

Gambar 2. Flowchart metode k-modes

Pada gambar 2 Flowchart Metode Certainty Factor proses yang pertama kali proses input data gelaja, lalu kita hitung nilai $\mathrm{CF}$ (gejala) berdasarkan nilai yang didapatkan dari gejala, untuk perhitungan $\mathrm{CF}$ (gejala) dapat menggunakan persamaan berikut untuk single premis rule:

$C F_{\text {gejala }}=C F_{\text {user }} \times C F_{\text {pakar }}$

untuk premis gejala yang lebih dari satu maka digunakan persamaan berikut untuk perhitungannya:

$C F_{(A A N D B)}=\operatorname{Min}\left(C F_{(A)}, C F_{(B)}\right) \times C F_{\text {rule }}$

$C F_{(A O R B)}=\operatorname{Min}\left(C F_{(A)}, C F_{(B)}\right) \times C F_{\text {rule }}$ 
Apabila terdapat kaidah dengan kesimpulan yang serupa (similiary concluded rules) atau lebih dari satu gejala, maka CF selanjutnya dihitung dengan persamaan :

$$
C F_{\text {Combine }}=C F_{\text {Fold }}+C F_{\text {gejala }} \times\left(1-C F_{\text {Fold }}\right)
$$

\subsection{Flowchart Sistem}

\section{(3.4)}

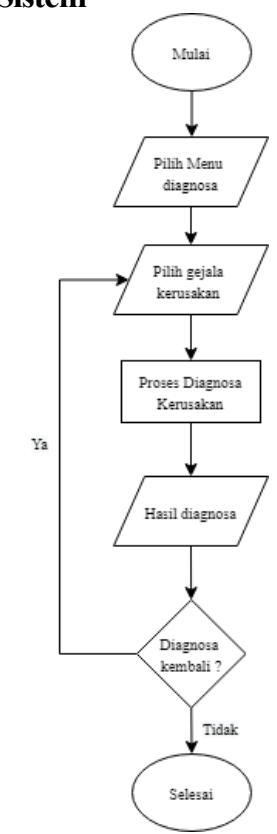

Gambar 3. Flowchart sistem

Pada gambar 3 Flowchart sistem menjelaskan alur dari sistem yang dibuat. Mulai dari melakukan login dengan menginputkan username dan password, login akan dicek dahulu apakah username dan password yang diinputkan sudah benar. Jika benar maka akan masuk ke halaman awal. Lalu pengguna akan mengisi data gejala kerusakan sesuai dengan gelaja yang dialami pada mobil pengguna, jika susah maka akan dilakukan diagnose sesuai dengan gejala yang dialami, jika sudah akan muncul hasil diagnosis. dan apabila ingin melakukan diagnose ulang user dapat melakukannya dengan mengisikan gejala yang dialami untuk melakukan diagnose ulang dan apabila tidak maka alur akan selesai.

\section{HASIL DAN PEMBAHASAN}

\subsection{Implementasi Sistem}

\subsubsection{Halaman dashboard}

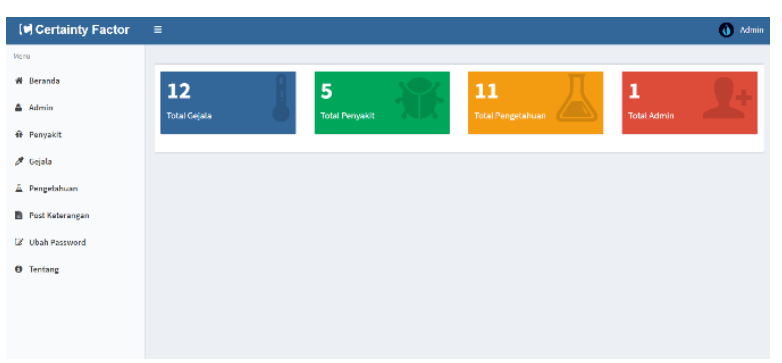

Gambar 4. Tampilan halaman utama
Pada gambar 4 merupakan halaman dashboard yang berisi menu - menu sistem pakar diagnosis kerusakan pada mobil Daihatsu.

\subsubsection{Halaman data gejala}

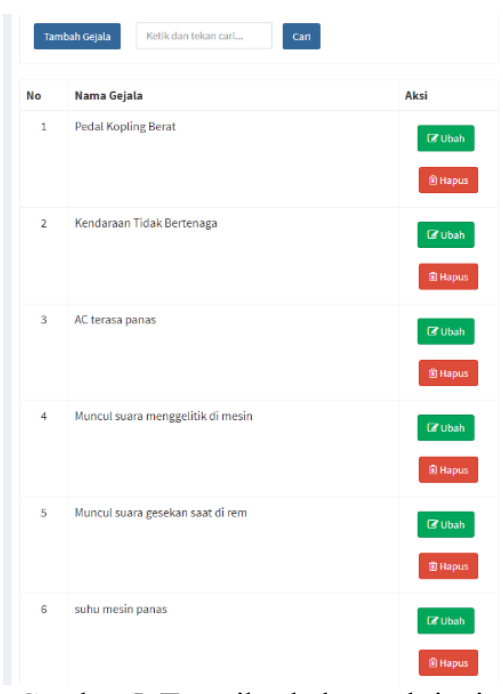

Gambar 5. Tampilan halaman kriteria

Pada Halaman ini admin dapat menambahkan, mengubah serta menghapus contoh gejala yang terjadi pada mobil user.

\subsubsection{Tampilan data kerusakan}

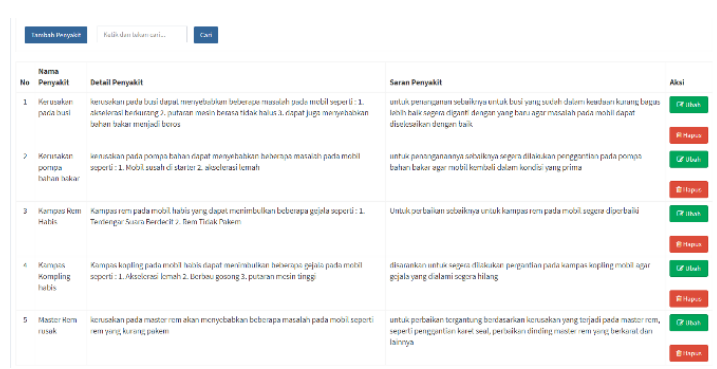

Gambar 6. Tampilan halaman data kerusakan

Pada gambar 6 merupakan Halaman Kerusakan menampilkan data kerusakan beserta detail serta saran untuk kerusakan yang dialami.

\subsubsection{Halaman data pengetahuan}

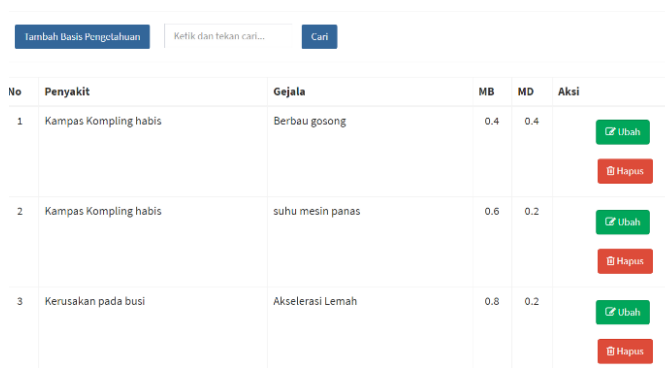

Gambar 7. Tampilan data pengetahuan 
Pada gambar 7 merupakan Halaman pengetahuan berisi data kerusakan dan gejala yang dialami jika terdapat kerusakan tersebut dan terdapat pula nilai $\mathrm{MB}$ serta MD.

\subsubsection{Halaman diagnosa}

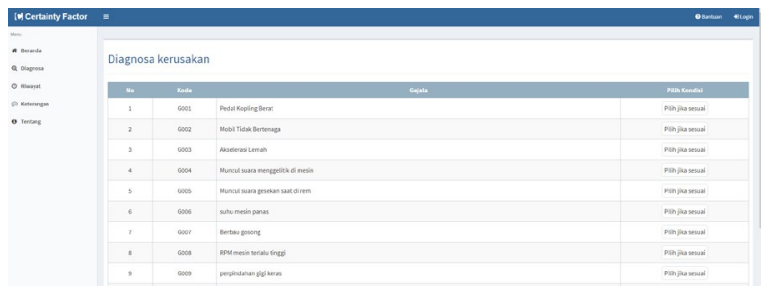

Gambar 8. Tampilan halaman diagnosa

Pada gambar 8 merupakan Halaman dimana pengguna dapat melakukan proses diagnose kerusakan pada mobil pengguna

\subsubsection{Tampilan halaman riwayat konsultasi}

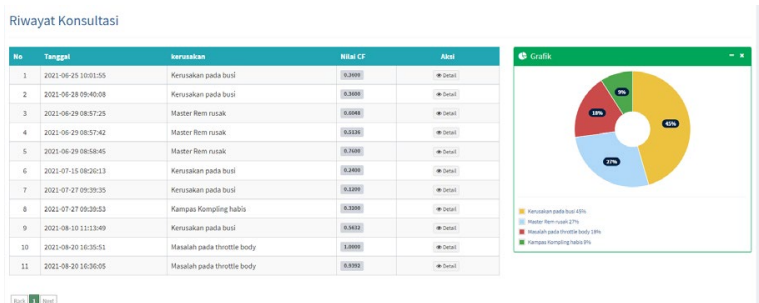

Gambar 9. Halaman riwayat konsultasi

Pada Halaman riwayat konsultasi pengguna dapat melihat hasil diagnosis yang pernah dilakukan sebelumnya oleh pengguna.

\subsection{Pengujian Metode}

\subsubsection{Pengujian metode certainty factor}

Tabel 1. tabel gejala

\begin{tabular}{|c|l|}
\hline Kode & \multicolumn{1}{|c|}{ Nama gejala } \\
\hline G001 & Pedal kopling berat \\
\hline G002 & Mobil Tidak Bertenaga \\
\hline G003 & Akselerasi Lemah \\
\hline G004 & Muncul suara menggelitik di mesin \\
\hline G005 & Muncul suara gesekan saat di rem \\
\hline G006 & suhu mesin panas \\
\hline G007 & Berbau gosong \\
\hline G008 & RPM mesin terlalu tinggi \\
\hline G009 & perpindahan gigi keras \\
\hline G010 & Kopling keras/selip \\
\hline G011 & Rem kurang pakem \\
\hline G012 & Rem terasa dalam \\
\hline G013 & mesin tersendak setiap di gas \\
\hline G014 & Minyak rem mulai berkurang \\
\hline G015 & Mobil susah dihidupkan \\
\hline G016 & mesin mati mendadak \\
\hline G017 & terdapat suara dan getaran pada pompa \\
\hline G018 & mesin berasa pincang/brebet \\
\hline G019 & Terjadi Knocking \\
\hline
\end{tabular}

\begin{tabular}{|l|l|}
\hline G020 & Terdapat bunyi dengung pada roda \\
\hline G021 & RPM Mesin naik turun \\
\hline G022 & Lampu check engine menyala \\
\hline G023 & Performa mesin menurun \\
\hline G024 & Keausan permukaan \\
\hline G025 & Lampu abs menyala \\
\hline
\end{tabular}

Tabel 2. tabel gejala

\begin{tabular}{|c|c|c|c|}
\hline Kode & $\begin{array}{c}\text { Nama } \\
\text { kerusakan }\end{array}$ & Detail kerusakan & Saran kerusakan \\
\hline 1 & $\begin{array}{l}\text { Kerusakan } \\
\text { pada busi }\end{array}$ & $\begin{array}{l}\text { kerusakan pada busi } \\
\text { dapat menyebabkan } \\
\text { beberapa masalah pada } \\
\text { mobil seperti : } 1 . \\
\text { akselerasi berkurang } 2 . \\
\text { putaran mesin berasa } \\
\text { tidak halus } 3 \text {. dapat } \\
\text { juga menyebabkan } \\
\text { bahan bakar menjadi } \\
\text { boros }\end{array}$ & $\begin{array}{l}\text { untuk penanganan } \\
\text { sebaiknya untuk busi } \\
\text { yang sudah dalam } \\
\text { keadaan kurang bagus } \\
\text { lebih baik segera } \\
\text { diganti dengan yang } \\
\text { baru agar masalah } \\
\text { pada mobil dapat } \\
\text { diselesaikan dengan } \\
\text { baik }\end{array}$ \\
\hline 2 & $\begin{array}{l}\text { Kerusakan } \\
\text { pompa } \\
\text { bahan } \\
\text { bakar }\end{array}$ & $\begin{array}{l}\text { kerusakan pada pompa } \\
\text { bahan dapat } \\
\text { menyebabkan } \\
\text { beberapa masalah pada } \\
\text { mobil seperti : } 1 . \text { Mobil } \\
\text { susah di starter } 2 . \\
\text { akselerasi lemah }\end{array}$ & $\begin{array}{lr}\text { untuk penanganannya } \\
\text { sebaiknya segera } \\
\text { dilakukan penggantian } \\
\text { pada pompa bahan } \\
\text { bakar agar mobil } \\
\text { kembali dalam kondisi } \\
\text { yang prima }\end{array}$ \\
\hline 3 & $\begin{array}{l}\text { Kampas } \\
\text { Rem Habis }\end{array}$ & $\begin{array}{l}\text { Kampas rem pada } \\
\text { mobil habis yang dapat } \\
\text { menimbulkan } \\
\text { beberapa gejala seperti } \\
: 1 \text {. Terdengar Suara } \\
\text { Berdecit 2. Rem Tidak } \\
\text { Pakem }\end{array}$ & $\begin{array}{lrr}\text { Untuk } & \text { perbaikan } \\
\text { sebaiknya } & \text { untuk } \\
\text { kampas rem } & \text { pada } \\
\text { mobil } & & \text { segera } \\
\text { diperbaiki } & & \end{array}$ \\
\hline 4 & $\begin{array}{l}\text { Kampas } \\
\text { Kompling } \\
\text { habis }\end{array}$ & $\begin{array}{l}\text { Kampas kopling pada } \\
\text { mobil habis dapat } \\
\text { menimbulkan } \\
\text { beberapa gejala pada } \\
\text { mobil seperti : } 1 . \\
\text { Akselerasi lemah } 2 . \\
\text { Berbau gosong } 3 . \\
\text { putaran mesin tinggi }\end{array}$ & $\begin{array}{lr}\text { disarankan } & \text { untuk } \\
\text { segera } & \text { dilakukan } \\
\text { pergantian } & \text { pada } \\
\text { kampas kopling mobil } \\
\text { agar gejala yang } \\
\text { dialami segera hilang }\end{array}$ \\
\hline 5 & $\begin{array}{l}\text { Master } \\
\text { Rem rusak }\end{array}$ & $\begin{array}{l}\text { kerusakan pada } \\
\text { master rem akan } \\
\text { menyebabkan } \\
\text { beberapa masalah } \\
\text { pada mobil seperti } \\
\text { rem yang kurang } \\
\text { pakem }\end{array}$ & $\begin{array}{l}\text { untuk perbaikan } \\
\text { tergantung } \\
\text { berdasarkan kerusakan } \\
\text { yang terjadi pada } \\
\text { master rem, seperti } \\
\text { penggantian karet seal, } \\
\text { perbaikan dinding } \\
\text { master rem yang } \\
\text { berkarat dan lainnya }\end{array}$ \\
\hline 6 & $\begin{array}{l}\text { Kerusakan } \\
\text { pada Aki }\end{array}$ & $\begin{array}{l}\text { Mesin tidak bisa } \\
\text { dihidupkan (starter), } \\
\text { Lampu mobil tidak } \\
\text { terang (redup), } \\
\text { Suara klakson mulai } \\
\text { tidak nyaring. }\end{array}$ & $\begin{array}{l}\text { Cara pertama yang } \\
\text { harus kamu lakukan } \\
\text { untuk membuat aki } \\
\text { mobil awet adalah } \\
\text { tidak menambah } \\
\text { beban standar pada } \\
\text { aki bawaan mobil. } \\
\text { Kondisi ini akan } \\
\text { membuat aki jadi } \\
\text { cepat habis. Selain } \\
\text { itu, kamu juga harus } \\
\text { memastikan semua } \\
\text { lampu mobil dalam } \\
\text { keadaan mati saat } \\
\text { mobil berhenti atau } \\
\text { parkir dalam jangka } \\
\text { waktu yang cukup } \\
\text { lama. Tidak } \\
\text { berhenti sampai } \\
\text { disitu, jika mobil } \\
\text { kamu jarang }\end{array}$ \\
\hline
\end{tabular}




\begin{tabular}{|c|c|c|c|}
\hline & & & $\begin{array}{l}\text { digunakan, } \\
\text { sebaiknya nyalakan } \\
\text { mesin setiap tiga } \\
\text { hari sekali dengan } \\
\text { durasi sekitar } 10 \\
\text { hingga } 15 \text { menit, } \\
\text { agar aki mobil tetap } \\
\text { berad }\end{array}$ \\
\hline 7 & $\begin{array}{l}\text { Kerusakan } \\
\text { pada koil }\end{array}$ & $\begin{array}{l}\text { Fungsi coil adalah } \\
\text { untuk menyuplai } \\
\text { tegangan ke busi } \\
\text { yang berasal dari } \\
\text { baterai. Tegangan } \\
\text { yang diperoleh dari } \\
\text { baterai } 12 \text { volt akan } \\
\text { dinaikkan menjadi } \\
10 \text { - 20k Volt yang } \\
\text { disalurkan ke busi. } \\
\text { Tujuannya agar busi } \\
\text { dapat membakar } \\
\text { sempurna campuran } \\
\text { udara dan bahan } \\
\text { bakar. Jika percikan } \\
\text { busi kecil, maka } \\
\text { pembakaran yang } \\
\text { terjadi pada ruang } \\
\text { bakar tidak akan } \\
\text { maksimal. } \\
\text { Akibatnya, diawal } \\
\text { mesin dihidupkan } \\
\text { akan mengalami } \\
\text { delay yang lama. } \\
\text { Salah satu } \\
\text { peyebabnya adalah } \\
\text { coil tidak bisa lagi } \\
\text { membangkitkan } \\
\text { tegangan }\end{array}$ & $\begin{array}{l}\text { cara mudah } \\
\text { mengatasi koil } \\
\text { rusak saat panas, } \\
\text { bisa dengan cara } \\
\text { mengompress koil } \\
\text { menggunakan lap } \\
\text { basah, ini adalah } \\
\text { penanganan } \\
\text { sementara tetapi } \\
\text { harus dilakukan } \\
\text { pergantian pada koil }\end{array}$ \\
\hline 8 & $\begin{array}{l}\text { Kerusakan } \\
\text { pada } \\
\text { Injektor }\end{array}$ & $\begin{array}{l}\text { kerusakan pada } \\
\text { injektor dapat } \\
\text { menyebabkan } \\
\text { beberapa gejala } \\
\text { seperti mobil mati } \\
\text { mendadak, susah di } \\
\text { starter, mesin brebet }\end{array}$ & $\begin{array}{l}\text { untuk saran } \\
\text { perbaikan nya yaitu } \\
\text { selalu pastikan fuel } \\
\text { filter bersih. } \\
\text { dilakukan } \\
\text { pembersihan pada } \\
\text { injector. }\end{array}$ \\
\hline 9 & $\begin{array}{l}\text { Kerusakan } \\
\text { pada } \\
\text { bearing } \\
\text { roda }\end{array}$ & $\begin{array}{l}\text { Bearing roda yang } \\
\text { rusak biasanya } \\
\text { menunjukkan gejala } \\
\text { dan tanda yang } \\
\text { cukup jelas yang } \\
\text { bisa dirasakan di } \\
\text { ruang kemudi. } \\
\text { Beberapa cirinya } \\
\text { adalah terdapat } \\
\text { dengung pada roda, } \\
\text { dan bisa juga terasa } \\
\text { pada kemudi yang } \\
\text { bergetar }\end{array}$ & $\begin{array}{l}\text { untuk kerusakan } \\
\text { pada bearing, jika } \\
\text { bisa disegerakan } \\
\text { untuk dilakukan } \\
\text { penggantiakn } \\
\text { karena jika tidak } \\
\text { bisa membahayakan } \\
\text { bagi pengguna, } \\
\text { karena bisa } \\
\text { menyebabkan } \\
\text { masalah lain seperti } \\
\text { roda mobil yang } \\
\text { terkunci, rem mobil } \\
\text { macet, as roda yang } \\
\text { dapat berpotensi } \\
\text { patah dan lainnya. }\end{array}$ \\
\hline 10 & $\begin{array}{l}\text { Masalah } \\
\text { pada } \\
\text { throttle } \\
\text { body }\end{array}$ & $\begin{array}{l}\text { Throttle body } \\
\text { merupakan } \\
\text { komponen dari } \\
\text { sistem pemasukan } \\
\text { udara atau air intake } \\
\text { system. agar } \\
\text { performa mesin } \\
\text { dapat maksimal } \\
\text { karena itu } \\
\text { dibutuhkan } \\
\text { kombinasi antara } \\
\text { udara dan bahan } \\
\text { bakar yang masuk } \\
\text { ke dalam ruang }\end{array}$ & $\begin{array}{l}\text { untuk masalah pada } \\
\text { throttle body } \\
\text { mungkin dapat } \\
\text { dicek terlebih } \\
\text { dahulu kondisinya, } \\
\text { dan dapat dilakukan } \\
\text { pembersihan pada } \\
\text { throttle body, } \\
\text { namun jika kondisi } \\
\text { throttle body sudah } \\
\text { rusak sebaiknya } \\
\text { dilakukan } \\
\text { pergantian terhadap } \\
\text { throttle body }\end{array}$ \\
\hline
\end{tabular}

\begin{tabular}{|l|l|l|}
\hline & bakar harus pas. jika & tersebut. \\
terdapat masalah & \\
pada throttle body & \\
maka dapat & \\
berdampak pada & \\
performa pada & \\
& mesin, karena & \\
jumlah udara yang & \\
& masuk kedalam & \\
& ruang bakar tidak & \\
pas sesuai dengan & \\
& kebutuhan mesin. & \\
\hline
\end{tabular}

Pembuatan tabel matriks untuk membantu dalam mengorganisasi pengetahuan kerusakan kendaraan agar lebih mudah dipahami

Tabel 3. Tabel Matriks Pengetahuan

\begin{tabular}{|c|c|c|c|c|c|c|c|c|c|c|}
\hline Gejala & $\mathrm{K} 1$ & $\mathrm{~K} 2$ & $\mathrm{~K} 3$ & $\mathrm{~K} 4$ & K5 & K6 & K7 & K8 & K9 & K10 \\
\hline 1 & & & & $\checkmark$ & & & & & & \\
\hline 2 & & & $\checkmark$ & & & & $\checkmark$ & & & \\
\hline 3 & $\checkmark$ & $\checkmark$ & & & & & & & & \\
\hline 4 & $\checkmark$ & & & & & & & & & \\
\hline 5 & & & & & & & & & & \\
\hline 6 & & & & $\checkmark$ & & & & & & \\
\hline 7 & & & & $\checkmark$ & & & & & & \\
\hline 8 & $\checkmark$ & & & $\checkmark$ & & & & & & \\
\hline 9 & & & & $\checkmark$ & & & & & & \\
\hline 10 & & & & $\checkmark$ & & & & & & \\
\hline 11 & & & & & $\checkmark$ & & & & & \\
\hline 12 & & & & & $\checkmark$ & & & & & \\
\hline 13 & $\checkmark$ & & & & & & & & & \\
\hline 14 & & & $\checkmark$ & & & & & & & \\
\hline 15 & & $\checkmark$ & & & . & $\checkmark$ & $\checkmark$ & $\checkmark$ & & \\
\hline 16 & & & & & $\checkmark$ & $\checkmark$ & & $\checkmark$ & & \\
\hline 17 & & $\checkmark$ & & & & & & & & \\
\hline 18 & & & & & & & $\checkmark$ & $\checkmark$ & & \\
\hline 19 & $\checkmark$ & & & & & & & & & \\
\hline 20 & & & & & & & & & $\checkmark$ & \\
\hline 21 & & & & & & & & & & $\checkmark$ \\
\hline 22 & & & & & & & & & & $\checkmark$ \\
\hline 23 & & & & & & & & & & $\checkmark$ \\
\hline 24 & & & & & & & & & $\checkmark$ & \\
\hline 25 & & & & & & & & & $\checkmark$ & \\
\hline
\end{tabular}

Untuk menentukan keterangan factor keyakinan dari pakar dinilai dari CFcombine dengan berpedoman dari table interpretasi (term) certainty factor, adapun table tersebut dapat dilihat sebagai berikut:

Tabel 4. Interpretasi Term Nilai CF

\begin{tabular}{|l|l|}
\hline Kondisi & CF \\
\hline Sangat Yakin & 1 \\
\hline Yakin & 0,8 \\
\hline Cukup Yakin & 0,6 \\
\hline Sedikit Yakin & 0,4 \\
\hline Tidak & 0 \\
\hline
\end{tabular}

Sebagai contoh berikut perhitungan untuk kerusakan K05 dengan gejala yang telah dipilih oleh user seperti pada gambar berikut ini. 


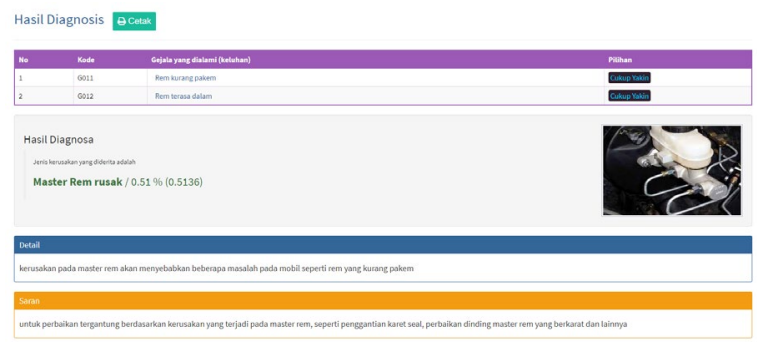

Gambar 10. Hasil diagnosa

Pada gambar 4.7 untuk gejala yang dipilih oleh pengguna adalah rem kurang pakem serta rem terasa dalam, dengan pilihan kondisi cukup yakin.

Untuk penghitungan pada metode yaitu seperti dibawah ini.

$C F_{\text {Pakar }} G D 11=M B-M D=0,6-0=0,6$

$C F_{\text {Pakar }} G D 12=M B-M D=0,6-0,2=0,4$

Kemudian nilai $\mathrm{CF}$ dihitung menggunakan persamaan dibawah ini

$C F_{\text {gejala }}=C F_{\text {gejala }} \times C F_{\text {Pakar }}$

$C F_{11}=0,6 \times 0,6=0,36$

$C F_{12}=0,6 \times 0,4=0,24$

Karena lebih dari satu gejala maka untuk menentukan CF kerusakan selanjutnya digunakan persamaan $C F_{\text {combine }}=\left(C F_{11}, C F_{12}\right)=C F_{11}+C F_{12} \times$ $\left(1-C F_{11}\right)$

Sehingga menjadi:

$C F_{\text {combine }}=\left(C F_{11}\right.$

$C F_{\text {fold }}=0,5136$

Untuk mendapatkan nilai dalam bentuk presentase, maka menggunakan rumus $\mathrm{CF}$ presentasi sebagai berikut:

$C F_{\text {presentasi }}=C F_{\text {fold }} \times 100=0,5136 \times 100=51,36 \%$

\subsection{Pengujian Fungsional dengan black box}

Pengujian sistem merupakan proses menampilkan sistem dengan maksud untuk menemukan adanya kesalahan atau tidak pada fiturfitur aplikasi. Hasil pengujian sistem menggunakan metode black box ditunjukkan pada Tabel 4.4 berikut ini :

Tabel 5. Pengujian fungsional

\begin{tabular}{|c|c|c|c|c|}
\hline $\begin{array}{l}\mathbf{N} \\
\mathbf{0}\end{array}$ & Pengujian & Nama Event & $\begin{array}{l}\text { Hasil Yang } \\
\text { Diharapkan }\end{array}$ & Kesimpulan \\
\hline \multirow[t]{4}{*}{1} & $\begin{array}{l}\text { Halaman } \\
\text { Kerusakan }\end{array}$ & $\begin{array}{l}\text { Klik button } \\
\text { tambah } \\
\text { kerusakan }\end{array}$ & $\begin{array}{l}\text { Penambahan } \\
\text { data pada } \\
\text { halaman } \\
\text { kerusakan }\end{array}$ & Berhasil \\
\hline & & $\begin{array}{l}\text { Klik button } \\
\text { cari }\end{array}$ & $\begin{array}{l}\text { Pencarian } \\
\text { nama } \\
\text { kerusakan }\end{array}$ & Berhasil \\
\hline & & $\begin{array}{l}\text { Klik button } \\
\text { ubah }\end{array}$ & $\begin{array}{l}\text { Pengubahan } \\
\text { data kerusakan }\end{array}$ & Berhasil \\
\hline & & Klik Hapus & $\begin{array}{l}\text { Penghapusan } \\
\text { data kerusakan }\end{array}$ & Berhasil \\
\hline \multirow[t]{3}{*}{2} & $\begin{array}{l}\text { Halaman } \\
\text { gejala }\end{array}$ & $\begin{array}{l}\text { Klik button } \\
\text { tambah } \\
\text { gejala }\end{array}$ & $\begin{array}{l}\text { Penambahan } \\
\text { data pada } \\
\text { halaman gejala }\end{array}$ & Berhasil \\
\hline & & $\begin{array}{l}\text { Klik button } \\
\text { cari }\end{array}$ & $\begin{array}{l}\text { Pencarian } \\
\text { nama gejala }\end{array}$ & Berhasil \\
\hline & & Klik button & Pengubahan & Berhasil \\
\hline
\end{tabular}

\begin{tabular}{|l|l|l|l|l|}
\hline & & ubah & data gejala & \\
\hline 3 & $\begin{array}{l}\text { Kalaman } \\
\text { pengetahuan }\end{array}$ & $\begin{array}{l}\text { Klik button } \\
\text { tambah } \\
\text { pengetahuan } \\
\text { data gejala }\end{array}$ & $\begin{array}{l}\text { Penambahan } \\
\text { data pada } \\
\text { halaman } \\
\text { pengetahuan }\end{array}$ & Berhasil \\
\hline & & $\begin{array}{l}\text { Klik button } \\
\text { cari }\end{array}$ & $\begin{array}{l}\text { Pencarian } \\
\text { nama } \\
\text { kerusakan }\end{array}$ & Berhasil \\
\hline & $\begin{array}{l}\text { Klik button } \\
\text { ubah }\end{array}$ & $\begin{array}{l}\text { Pengubahan } \\
\text { data } \\
\text { pengetahuan }\end{array}$ & Berhasil \\
\hline 5 & $\begin{array}{l}\text { Halaman } \\
\text { diagnosa }\end{array}$ & $\begin{array}{l}\text { Klik pilih } \\
\text { kondisi }\end{array}$ & $\begin{array}{l}\text { Kenghapusan } \\
\text { data } \\
\text { pengetahuan }\end{array}$ & Bilihan kondisi \\
\hline & $\begin{array}{l}\text { Klik tombol } \\
\text { diagnosa }\end{array}$ & $\begin{array}{l}\text { Tampilan data } \\
\text { hasil diagnosa }\end{array}$ & Berhasil \\
\hline & $\begin{array}{l}\text { Klik tombol } \\
\text { cetak }\end{array}$ & $\begin{array}{l}\text { Export hasil } \\
\text { diagnosa }\end{array}$ & Berhasil \\
\hline 6 & $\begin{array}{l}\text { Halaman } \\
\text { riwayat }\end{array}$ & $\begin{array}{l}\text { Klik button } \\
\text { detail }\end{array}$ & $\begin{array}{l}\text { Tampilan } \\
\text { detail diagnosa } \\
\text { yang pernah } \\
\text { dilakukan }\end{array}$ & Berhasil \\
\hline
\end{tabular}

\section{KESIMPULAN DAN SARAN}

\subsection{Kesimpulan}

Berikut ini adalah kesimpulan yang dapatkan setelah melakukan pembuatan aplikasi Sistem pakar diagnosis kerusakan pada mobil Daihatsu:

1. Aplikasi yang dibuat ini dapat menghasilkan $=0,3$ tpuf 0 , befupa_jenjis kerusakan serta gejala yang timbul serta menampilkan presentasi kemungkinan kerusakannya

2. Aplikasi sistem pakar ini menggunakan perhitungan metode certainty factor, dimana nilai keyakinan dari pakar akan dibandingkan dengan nilai keyakinan dari user sehinggaakan diperoleh nilai kepastian diagnosa sesuai kaidah perhitungan metode certainty factor.

\subsection{Saran}

Berdasarkan penelitian yang telah dilakukan, maka penulis dapat memberikan saran-saran untuk pengembangan selanjutnya antar lain :

1. Diharapkan website dapat di kembangkan ke dalam aplikasi mobile.

2. Menambahkan metode lain supaya hasil pengelompokan dari sistem bisa lebih baik lagi dan akurat

\section{DAFTAR PUSTAKA}

[1] Cahyadi, B. (2018). Sistem pakar diagnosis penyakit paru-paru menggunakan Metode Certainty Factor dengan Mesin Inferensi Forward Chaining berbasis Android. JATI (Jurnal Mahasiswa Teknik Informatika)

[2] Kurniawan, S. P. (2018). SISTEM PAKAR UNTUK DIAGNOSIS PENYAKIT ANEMIA MENGGUNAKAN METODE CERTAINTY FACTOR DENGAN MESIN INFERENSI FORWARD CHAINING BERBASIS WEB. 
JATI (Jurnal Mahasiswa Teknik Informatika)

[3] Gulo, C., \& Hasibuan, N. A. (2017). Perancangan Sistem Pakar Deteksi Kerusakan Mobil Honda Cr-V Dengan Menerapkan Metode Certainty Factor. KOMIK (Konferensi Nasional Teknologi Informasi dan Komputer)

[4] Nugroho, K., \& Sumiati, S. (2020). SISTEM PAKAR DIAGNOSIS KERUSAKAN KENDARAAN PADA MOBIL WULING CONFERO S MENGGUNAKAN METODE CERTAINTY FACTOR. JSiI (Jurnal Sistem Informasi)

[5] Satwika, I. B. D., \& Bagus, I. (2012). Rancang Bangun Sistem Diagnosis Kerusakan Pada Mobil Mengunakan Metode Forward Chaining. Jurnal Elektronik Ilmu Komputer: Universitas Udayana.

[6] Hakim, L., \& Musalini, U. (2004). Cara Cerdas
Menguasai Layout, Desain dan Aplikasi Web. Jakarta: PT Elex Media Komputindo.

[7] Maulana, A. A. (2016). SISTEM PAKAR DIAGNOSA GANGGUAN MESIN SEPEDA MOTOR (Doctoral dissertation, Universitas Negeri Semarang).

[8] Imron, I., Afidah, M. N., Nurhayati, M. S., Sulistiyah, S., \& Fatmawati, F. (2019). Sistem Pakar Diagnosa Kerusakan Mesin Sepeda Motor Transmission Automatic dengan Metode Forward Chaining Studi Kasus: AHASS 00955 Mitra Perdana. Jurnal Ilmiah Universitas Batanghari Jambi, 19(3), 544-553.

[9] Sutojo, T., E. Mulyanto, dan V. Suhartono. 2011. Kecerdasan Buatan. 99 Yogyakarta: Penerbit Andi Offset

[10] Kusumadewi, S. (2003). Artificial intelligence (teknik dan aplikasinya). 